\title{
Acetyl group migration across the saccharide units in oligomannoside model compound
}

\section{Lassfolk, Robert}

2019-01-30

Lassfolk, R , Rahkila , J , Johansson , M P , Ekholm , F S , Wärnå , J \& Leino , R 2019 , ' Acetyl group migration across the saccharide units in oligomannoside model compound ', Journal of the American Chemical Society , vol. 141 , no. 4 , pp. 1646-1654 . https://doi.org/10.1021/jacs.8b11563

http://hdl.handle.net/10138/308745

https://doi.org/10.1021/jacs.8b11563

unspecified

acceptedVersion

Downloaded from Helda, University of Helsinki institutional repository.

This is an electronic reprint of the original article.

This reprint may differ from the original in pagination and typographic detail.

Please cite the original version. 


\title{
Acetyl group migration across the saccharide units in oligomannoside model compound
}

\author{
Robert Lassfolk, ${ }^{\dagger}$ Jani Rahkila, ${ }^{\dagger}$ Mikael P.Johansson, ${ }^{\ddagger, \perp}$ Filip S. Ekholm, ${ }^{\ddagger}$ Johan Wärnå, ${ }^{\S}$ and Reko \\ Leino $*,+$ \\ †Johan Gadolin Process Chemistry Centre, Laboratory of Organic Chemistry, Åbo Akademi University, FI-20500 Åbo, \\ Finland \\ ‡Department of Chemistry, University of Helsinki, FI-00014 Helsinki, Finland \\ ${ }^{\perp}$ Helsinki Institute of Sustainability Science, HELSUS, Helsinki, Finland \\ $\S$ Johan Gadolin Process Chemistry Centre, Laboratory of Industrial Chemistry and Reaction Engineering, Åbo \\ Akademi University, FI-20500 Åbo, Finland
}

\begin{abstract}
Acetylated oligosaccharides are common in nature. While they are involved in several biochemical and biological processes, the role of the acetyl groups and the complexity of their migration has largely gone unnoticed. In this work, by combination of organic synthesis, NMR spectroscopy and quantum chemical modeling, we show that acetyl group migration is a much more complex phenomenon than previously known. By use of synthetic oligomannoside model compounds, we demonstrate, for the first time, that the migration of acetyl groups in oligosaccharides and polysaccharides may not be limited to transfer within a single monosaccharide moiety, but may also involve migration over a glycosidic bond between two different saccharide units. The observed phenomenon is not only interesting from the chemical point of view, but it also raises new questions about the potential biological role of acylated carbohydrates in nature.
\end{abstract}

\section{INTRODUCTION}

In nature, both linear and branched polysaccharides are found in all plants. Many polysaccharides also contain acetyl groups in different positions in their backbone or the side chains. Examples of naturally occurring partially acetylated polysaccharides are xyloglucans, ${ }^{1-4}$ arabinoxylans ${ }^{5-7}$ and mannans. ${ }^{8-13}$ Depending on their location in the plants, a broad variety in the degree of acetylation can be observed..$^{14}$ The degree of acetylation is controlled by the plant itself, inferring that the acetyl groups in nature may also play an important, albeit less investigated, biological function.15-17 Mannans, in particular, have been found to be partially acetylated in different plants. Most of the natural mannans can be acetylated in the 0-2, 0-3 or in some cases also in the 0-6 position.-13 In addition to mannose, these polysaccharides often contain other monosaccharide units in their backbone or side chains. Many of the natural mannans have a linear backbone consisting of $\beta-(1 \rightarrow 4)$ linkages with side chains connected to the 0-6 of the mannose, altering the flexibility of the chain..$^{18}$ The most common $\beta$-( $1 \rightarrow 4)$-linked mannan polysaccharides are illustrated in Figure $1 .{ }^{19}$ In the plants, these mannans may act as a storage for nonstarch carbohydrates, molecular recognition sites for pathogens and as signaling molecules for plant growth and development. ${ }^{20}$

The biological activity of mannans often extends beyond their natural role in the plant. Acetylated linear mannan (acemannan), isolated from Aloe vera, has been shown to
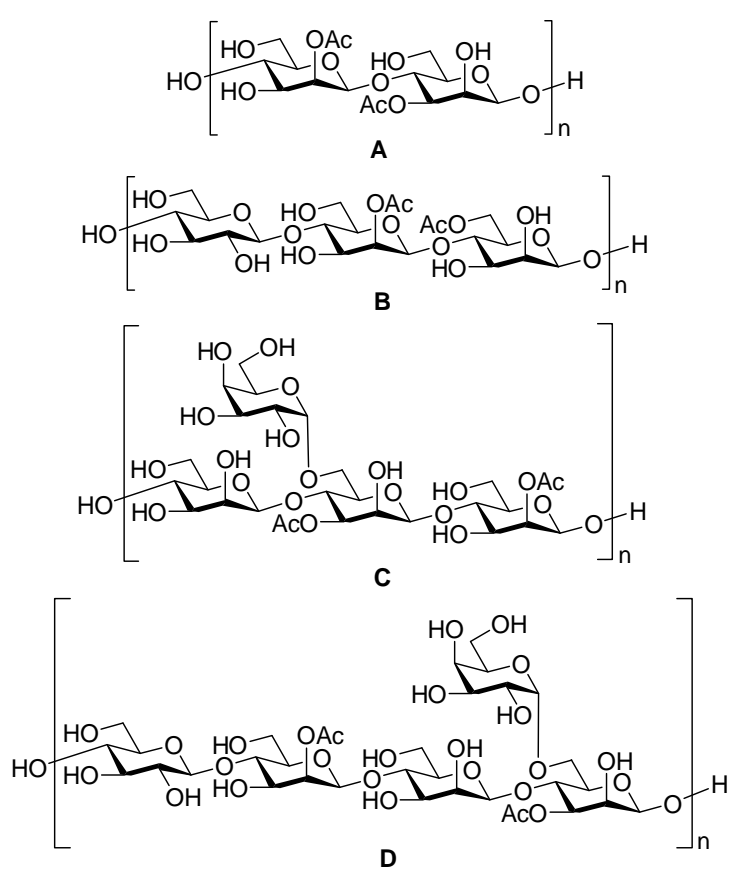

Figure 1. Structures of natural mannans: A: Acemannan, B: Glucomannan, C: Galactomannan, D: Galactoglucomannan.

inhibit the growth of cancer tumors. ${ }^{8}$ Acetylated glucomannans found in the orchid family (Dendrobium officinale) ${ }^{10}$ have been found to possess antioxidant activities, and it has been suggested that this biological activity is closely connected to the acetyl group pattern in 
addition to the glycosidic linkage types. ${ }^{21-23}$ Galactoglucomannan (GGM), in turn, is the most common hemicellulose in spruce (Picea abies). ${ }^{24,25}$ The GGM polysaccharide has been shown to exist in both nonacetylated and partially acetylated forms, both of which display biological activity with known applications. ${ }^{26}$

Generally, in nature, acetyl groups may be involved in various biological activation and deactivation processes of other natural compounds. ${ }^{27}$ Consequently, the frequently observed acetyl group migration in polysaccharides could also have important implications for the molecular recognition and other biosignaling processes occurring in the host plant. As a phenomenon, the migration of acyl groups was first documented by Emil Fischer in $1920,{ }^{28}$ and has since been investigated and demonstrated to take place in several different monosaccharides.29-31 In oligo- and polysaccharides, however, hitherto migration studies have only demonstrated that migration takes place between the neighboring hydroxyl groups, but more extensive studies are still lacking. ${ }^{32,33^{*}}$

The possible observation of acetyl group migration between the different monosaccharide units in an oligo- or polysaccharide could significantly impact and inspire future research on acetylated polysaccharides and their true biological role in nature. Here, by extensive NMRspectroscopic studies of $\beta$ - $(1 \rightarrow 4)$-linked oligomannosides, combined with molecular modeling, we provide new insights into the intramolecular acetyl group migration between the different constituent mannose units.

\section{RESULTS AND DISCUSSION}

To study the migration phenomenon in oligosaccharides, two partially acetylated $\beta-(1 \rightarrow 4)$-linked di- and trimannosides were synthesized (structures $\mathbf{1}$ and $\mathbf{2}$ in Figure 2). Two monosaccharide compounds $\mathbf{3}$ and $\mathbf{4}$ were also prepared to provide additional information on the possible migration mechanism. Synthesis of the targeted substrates was not straightforward and a number of challenges were encountered in the experimental work. These aspects of the study are addressed in more detail in the Supporting Information.

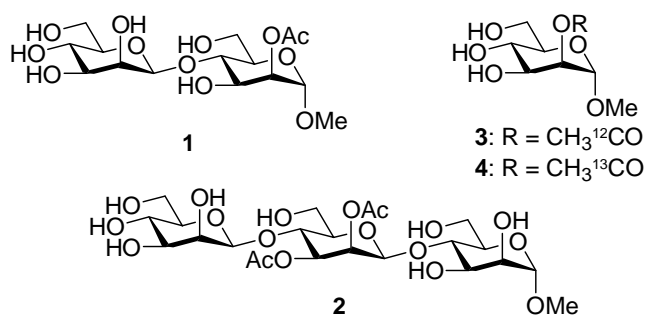

Figure

2. The $\beta$ - $(1 \rightarrow 4)$-linked di- and trisaccharide mannan model compounds and the model monosaccharides used for the acetyl group migration studies in this work.

Migration studies by NMR spectroscopy. Migration of the acetyl groups in the model di- and trisaccharides $\mathbf{1}$ and
2 was monitored by ${ }^{1} \mathrm{H}$ NMR spectroscopy, allowing adequate separation of the carbohydrate proton signals from the acetylated positions and, consequently, straightforward integration of the corresponding peak areas. The optimized migration conditions were adopted from our earlier work on acylated galactose-derivatives, where under acidic $\mathrm{pD}$ the acetyl groups were hydrolyzed without migration, while readily migrating under basic conditions. ${ }^{29}$ The previously determined optimal $\mathrm{pD}=8$ was used as a basis also for the present study. This $\mathrm{pD}$ is similar to the $\mathrm{pH}$ in plants, where the cytoplasmic $\mathrm{pH}$ resides between 7 to 8 depending on the organism and the conditions it lives in, making the migration conditions comparable or at least related to the ones existing in nature. ${ }^{34}$

For disaccharide 1, we initially set out to investigate the ratio between the anticipated 2-OAc and 3-OAc migration products $\mathbf{1 a}$ and $\mathbf{1 b}$ as a function of time. In addition, the potential migration of the 2-OAc or 3-OAc groups towards 0-6 of the same monosaccharide unit or a free hydroxyl position in the non-reducing end, across the glycosidic bond, was monitored. As shown in Figure 3, an equilibrium between $1 \mathbf{a}$ and $\mathbf{1 b}$ arises in $5 \mathrm{~h}$ at $\mathrm{pD}=8$, without any migration to the second monosaccharide unit or the 0-6 of the same carbohydrate unit, even after 330 days (not shown). The observed ratio between $\mathbf{1 a}$ and $\mathbf{1 b}$, approximately 60:40, corresponds well to the natural acetylated GGM, where $60-70 \%$ of the acetyl groups in the mannose unit reside on $0-2.12,35$ This also becomes evident from the migration rate constants where the rate of migration from $\mathbf{1 b}$ to $\mathbf{1 a}$ is almost twice higher than the opposite $\left(\mathrm{k}_{1}=0.343 \mathrm{~h}^{-1} \pm 0.0038, \mathrm{k}_{1}=0.564 \mathrm{~h}^{-1} \pm 0.0067\right)$. The energetic near-degeneracy of $\mathbf{1} \mathbf{a}$ and $\mathbf{1 b}$ was confirmed by quantum chemical calculations at CCSD(T)/ COSMO-RS level; 1a is minutely more stable, the simulated ratio being $63: 37(\Delta \mathrm{G}=+1.3 \mathrm{~kJ} / \mathrm{mol})$.

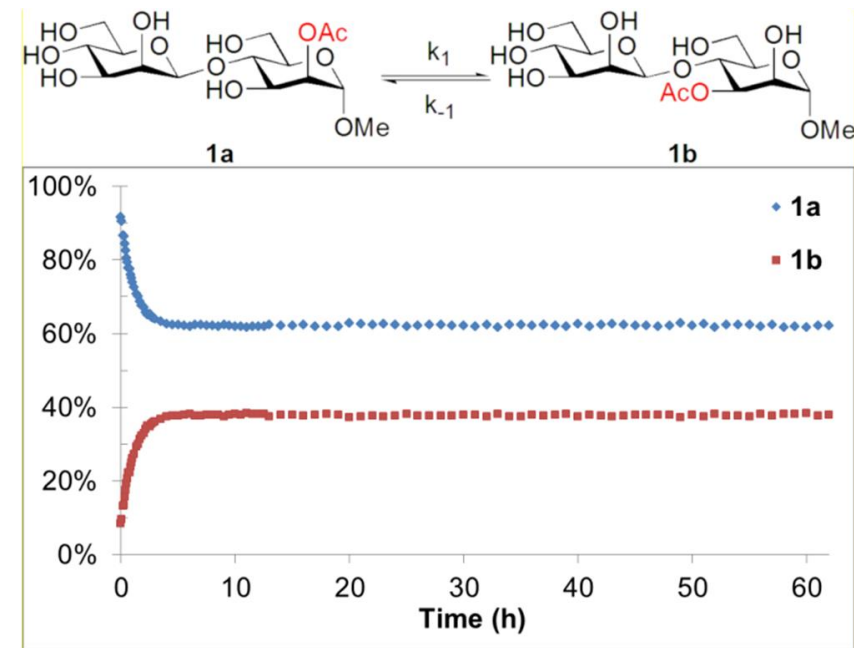

Figure 3. Migration path and data for $\mathbf{1}$ at $\mathrm{pD}=8$ and $25^{\circ} \mathrm{C}$ in buffered $\mathrm{D}_{2} \mathrm{O}$.

Scheme 1. Possible migration and hydrolysis in the trisaccharide model compound. For clarity, acetyl groups are marked in red and new free hydroxyl groups in blue color. 


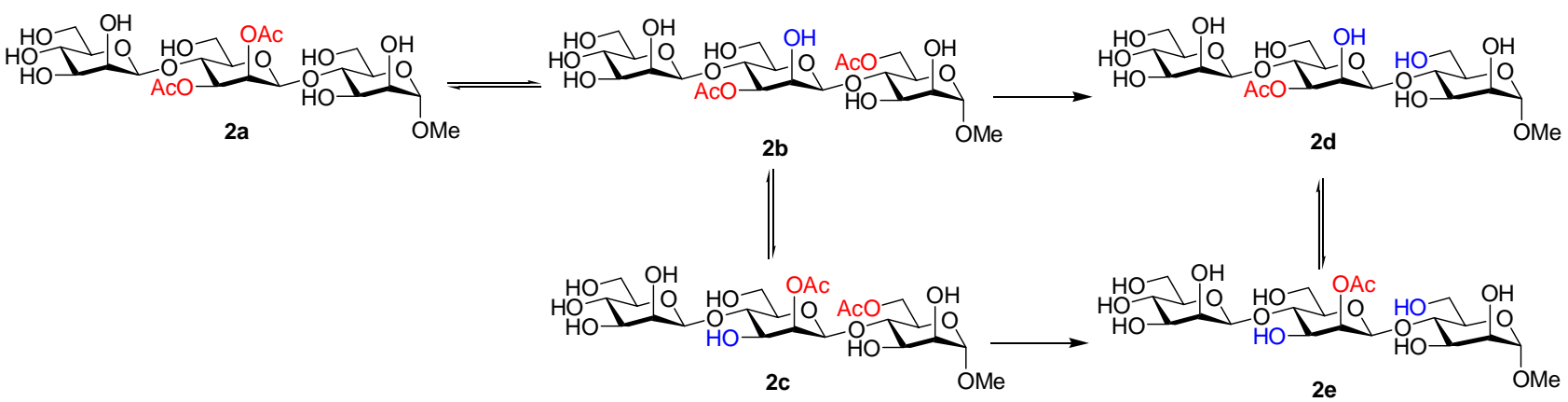

In the trisaccharide model compound 2 , both the $0-2$ and 0-3 positions of the middle monosaccharide unit are blocked by acetyl groups, preventing a similar migration pattern between the neighboring positions, as observed for the disaccharide 1 . However, when compound 2 was subjected to similar migration conditions, signals appeared in the ${ }^{1} \mathrm{H}$ NMR spectrum next to the ones arising from the $\mathrm{H}$ $2^{\prime}$ and $\mathrm{H}-3^{\prime}$ protons (i.e., the acetylated positions of the middle mannose unit). In addition, new signals were observed between 4.2 and $4.4 \mathrm{ppm}$, the typical region for signals from H-6 next to 0-6 acetyl groups, ${ }^{29}$ which could also be verified by the multiplicity edited HSQC spectra where the $\mathrm{CH}_{2}$ signals are seen as negative. This observation is, therefore, consistent with acetyl group migration between two non-neighboring positions.

After six weeks of migration, intensities of the new signals in the ${ }^{1} \mathrm{H}$ spectra were sufficiently high to allow the measurement of 1D-TOCSY spectra. As can be seen in Figure 4, the new monosaccharide units appear in pairs, e.g., 2A and $2 \mathrm{~B}$ having the acetyl group at the $0-2$ position, and $0 \mathrm{~A}$ and OB having no acetyl group. From the 1D-TOCSY and HSQC data it could be unambiguously concluded that one of the acetyl groups in the middle carbohydrate unit of compound $\mathbf{2}$ had migrated across a glycosidic bond to the 0-6 position of either the reducing or non-reducing end of the trisaccharide. Next, by routine 2D-NMR experiments it could be confirmed that the acetyl group had migrated towards the reducing end, by identifying an HMBC correlation between the anomeric position of the monosaccharide unit bearing the 6 - $\mathrm{OAc}$ and the $\mathrm{OCH}_{3}$ of the reducing end (Figure 5). This is also consistent with the fact that no migration between the different monosaccharide units was observed in the disaccharide model compound $\mathbf{1}$ where the acetyl group resided in the reducing end from the start. Finally, in the HMBC spectrum of compound 2, two units with similar shifts close to each other are observed due to the equilibrium between the 2-OAc and 3-OAc of the middle unit after migration or hydrolysis of one of the acetyl groups. Since no hydrolysis of the 0-2 or 0-3 acetyl groups was observed in the disaccharide model compound $\mathbf{1}$, even after 330 days, it appears more likely that the hydrolysis in compound 2 takes place from 0-6, similar to the galactosederivatives in our earlier work. ${ }^{29}$

The slow migration process inevitably leads to some hydrolysis during the monitoring process. $A$ piori, it could be argued that the observed shifting of the acetyl group across the monosaccharide units would not be a true migration, but rather the result of a reversible hydrolysis of an acetyl group from one position, which then reattaches to another free hydroxyl group in the molecule. For ruling out this possibility, methyl $\alpha$-D-mannopyranose and NaOAc (1 eq) were dissolved in the same buffer used for the migration studies and this mixture was monitored for 7 days by ${ }^{1} \mathrm{H}$ NMR spectroscopy. No (re)acetylation was observed under the investigated conditions. Furthermore, in case partial hydrolysis and reacetylation took place in the trisaccharide model compound $\mathbf{2}$, it is highly unlikely that such process would be regiospecific. Yet another type of artefact, resulting from intermolecular acetyl group migration, could be introduced by some type of coordination between two trisaccharide molecules in the buffer solution. This possibility was investigated by monitoring the migration process in compound 2 using three different concentrations $(1,5$ and $10 \mathrm{mg} / \mathrm{ml})$. If an intermolecular acetyl group migration would take place, the migration rate should be different for the different concentrations studied. No evidence of differences in the apparent migration rates in the samples with different concentrations was observed after 6 weeks of migration studies. Consequently, from these results it can be concluded that the acetyl group indeed migrates towards the reducing end, across a glycosidic bond (Scheme 1).

Kinetic studies similar to those performed for migration in the disaccharide $\mathbf{1}$ were tested also on compound $\mathbf{2}$. The considerably slower migration in $\mathbf{2}$ together with the low concentrations of the migration products made such calculations unreliable. Redesign of additional future experiments, starting from different time points of the overall migration process, will be needed to obtain accurate kinetic information for trisaccharide 2.

Modeling of the migration process. The observed acetyl group migration between two monosaccharide units requires a sufficiently short distance between the initial position of the acetyl group, and a free target hydroxyl group in the second saccharide unit. In general, the conformations of $\beta(1 \rightarrow 4)$-linked oligomannosides are similar to cellulose and, consequently, retain a good degree of flexibility. ${ }^{18,36}$ Therefore, it is well possible that 


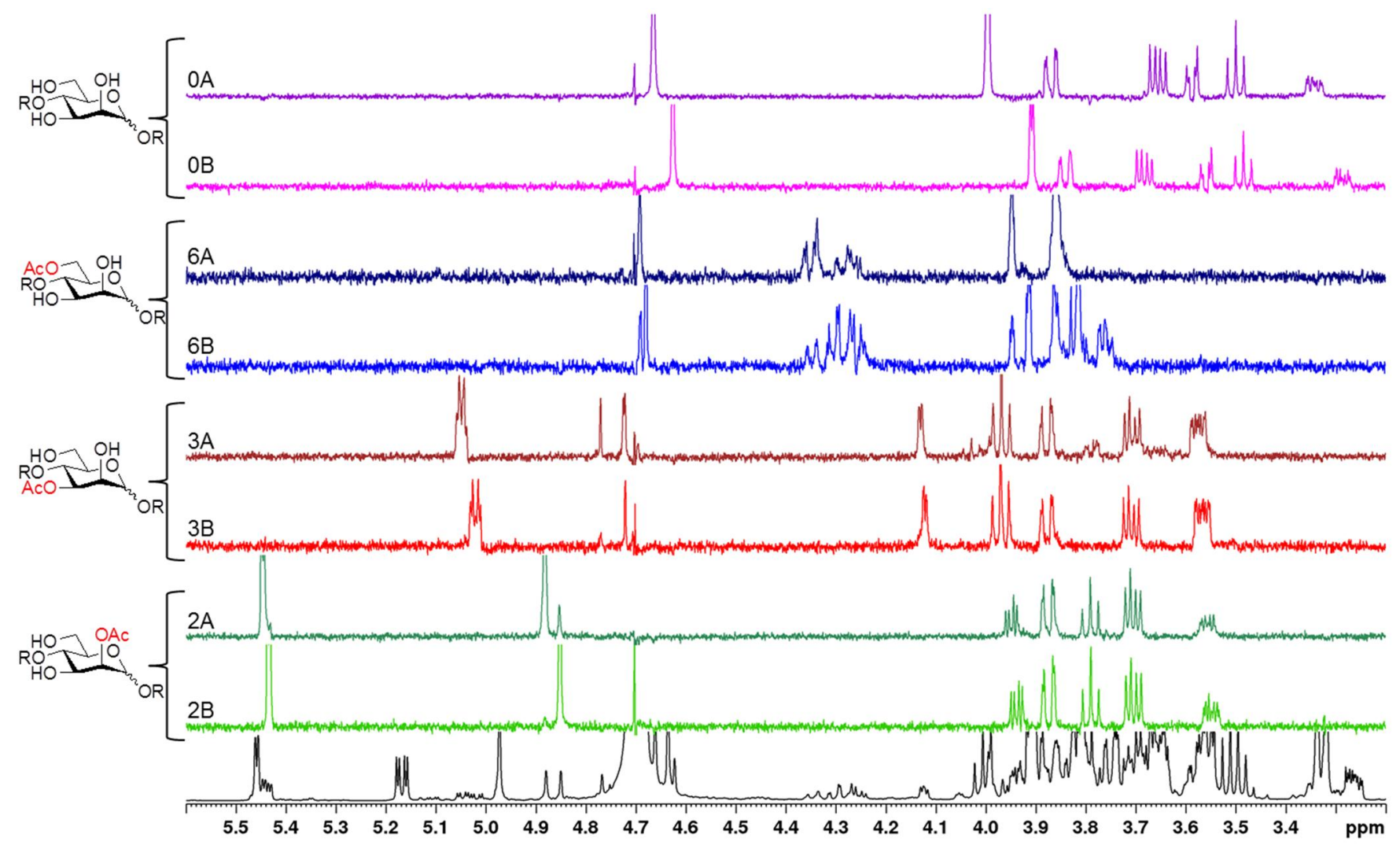

Figure 4. ${ }^{1} \mathrm{H}$ and 1D-TOCSY NMR-spectra of 2 and the selected peaks after 6 weeks of migration.

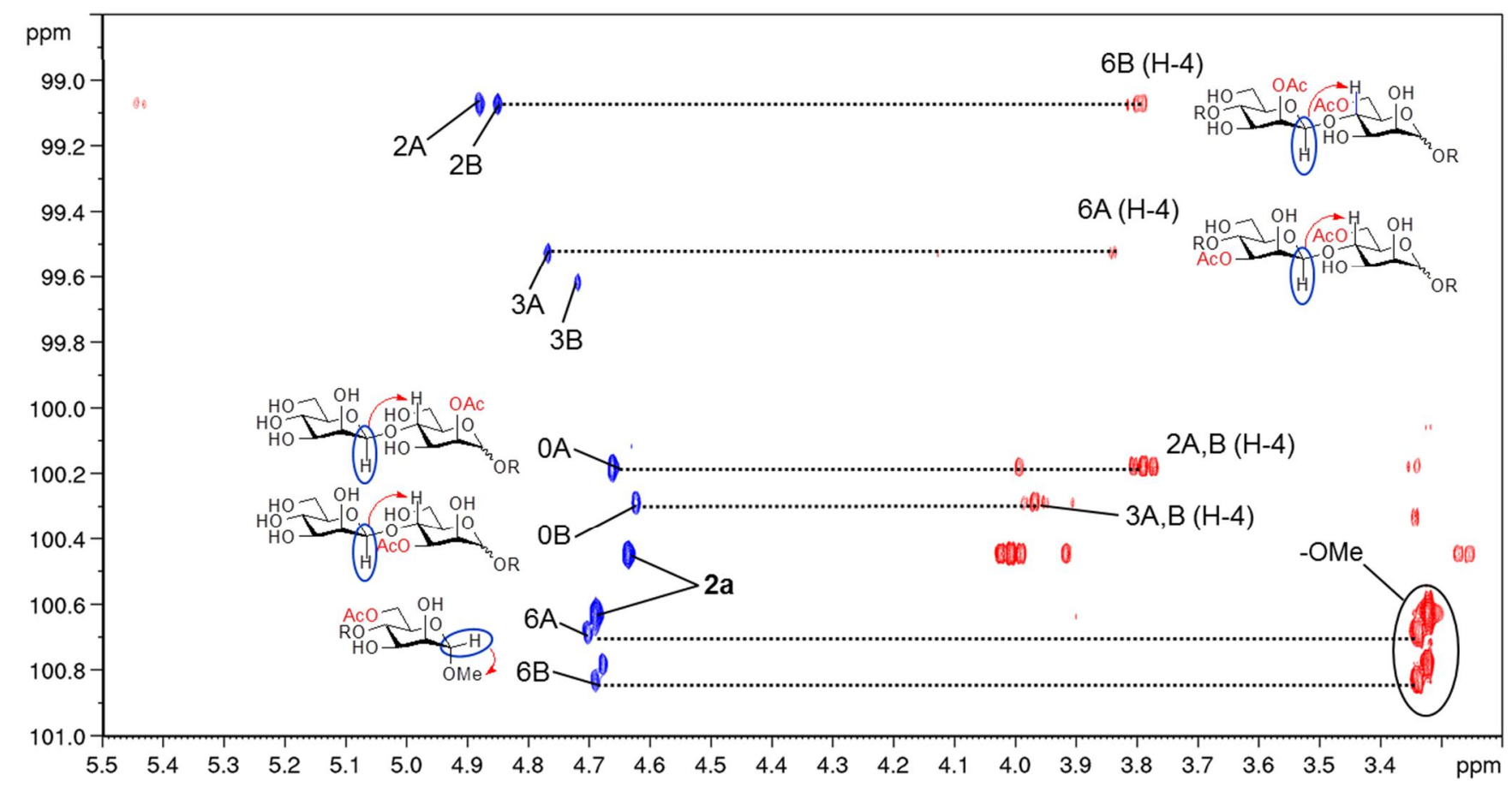

Figure 5. Correlations between HSQC of the anomeric signals (blue) and HMBC (red) of the 1D-TOCSY spectra shown in Figure 4 after 6 weeks of migration of trisaccharide 2 .

the intramolecular distance between the hydroxyl group at C6 and the acetyl group at C2' would approach each other within the requisite range for possible migration. In order to study this in more detail, quantum chemical simulations of the possible migration mechanism in compound $\mathbf{2}$ were performed, by studying the process of migration between 2a and $\mathbf{2 b}$ (Scheme 1). In the following, geometries were obtained at density function theory (DFT) level, while final electronic energies were computed at ab initio coupled cluster level [CCSD(T)]; for details, see the Methods section. 


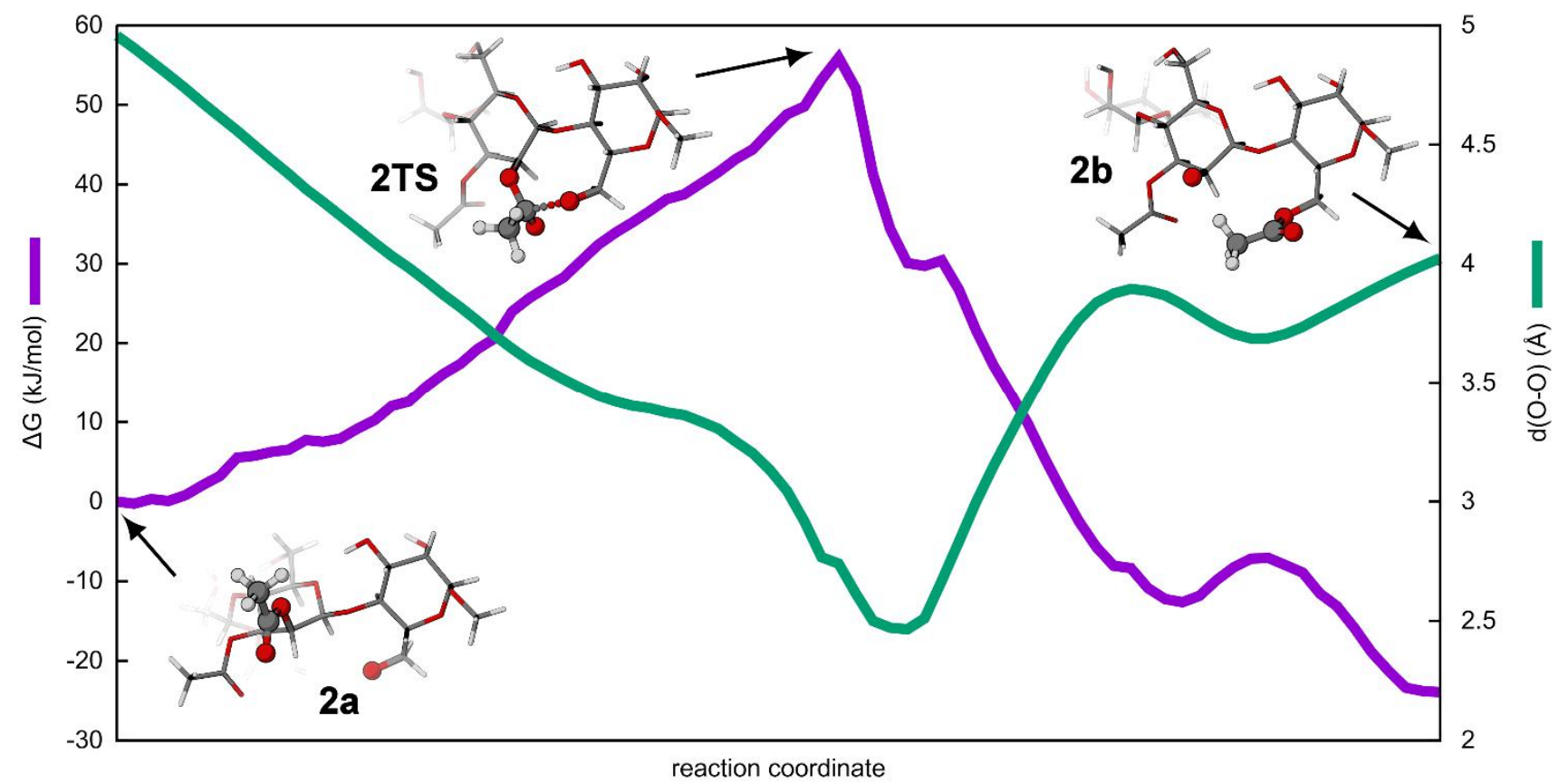

Figure 6. Reaction profile of the migration between the saccharide groups; relative Gibbs free energy (purple) and distance between donating and accepting oxygens (green) are shown, together with the molecular structures of $\mathbf{2 a}$, $\mathbf{2 b}$, and the transition state 2 TS connecting them.

Based on the calculations, it is evident that the migration process proceeds by initial deprotonation of the acetylaccepting hydroxyl group; without prior deprotonation, the migration barrier is computed to be prohibitively high, amounting to hundreds of $\mathrm{kJ} / \mathrm{mol}$. This is consistent with the earlier work where migration is fast at high $\mathrm{pH}$, slow at neutral $\mathrm{pH}$ and at acidic $\mathrm{pH}$ only hydrolysis of the acyl group takes place..$^{29}$ Figure 6 shows the profile of the migration reaction with the accepting hydroxyl group deprotonated. The structures of the initial state 2a, the intermediate transition state $\mathbf{2 T S}$, and the resulting migration product $\mathbf{2 b}$ are included. Notably, the three dimensional structure of $\mathbf{2 a}$ in Figure 6 is only one of the several possible conformational minima of this flexible molecule; compared to the 2D sketch of compound $\mathbf{2}$ in Scheme 1, the terminal saccharide in Figure 6 has rotated approximately halfa turn. The structure is, however, a representative example of a conformation where the leaving acetyl group can come in sufficiently close contact with the accepting $\mathrm{O}$ group on the opposite side of the $\beta$ - $(1 \rightarrow 4)$-linkage. As seen from Figure 6 , the distance between the donating and accepting oxygens steadily decreases along the reaction coordinate. At the transition state, the $\mathrm{O}-\mathrm{O}$ distance has decreased to ca 2.7 $\AA$. At the same time, a temporary nine-membered ring is formed, which includes the saccharide-bridge. The distance is further reduced after crossing the barrier, reaching a minimum below $2.5 \AA$. This is in accordance with Hammond's postulate, ${ }^{37}$ with an early transition state in this exothermic reaction. A movie of the full reaction path is given in the Supporting Information.

The activation free energy of the migration is computed to be $56 \mathrm{~kJ} / \mathrm{mol}$ at room temperature. This reaction barrier corresponds to a reaction half-life of less than a millisecond.
The reaction rate is thus limited by the dynamics of the chain, rather than the reaction barrier as such. The molecule is flexible, with several possible conformations enabled by the multitude of rather freely rotatable bonds and torsion angles. After deprotonation of the correct, accepting hydroxyl group, the trisaccharide still needs to reorient and rotate appropriately in order for the acetyl and $\mathrm{O}$ to come in sufficiently close contact for the migration to occur. Therefore, even if the migration itself requires surprisingly little in the form of activation energy, the preordering of the adjacent monosaccharide groups takes time; weeks, as shown by the NMR spectroscopic data in this work.

Mechanistic investigation. To further understand the acetyl group migration phenomenon, kinetic isotope effects were investigated. First, the acetylated monosaccharide model compound 3 (Figure 2) was investigated in the same buffer used for the oligosaccharides $\mathbf{1}$ and $\mathbf{2}$. As confirmed by the ${ }^{1} \mathrm{H}$ NMR spectral data, the expected path for acetyl group migration in monosaccharides, ${ }^{30}$ with clockwise migration towards the neighboring hydroxyl group, takes place (Scheme 2). As seen from Figure 7, the initial 2-OAc $\leftrightarrow$ 3-OAc migration between $\mathbf{3 a}$ and $\mathbf{3 b}$ is fast. This is further confirmed by the kinetic calculations where $\mathrm{k}_{1}$ and $\mathrm{k}_{-1}$ are higher than the other observed rate constants (Table 1). The acetyl group is clearly disfavored in position 0-4 with the concentration of $\mathbf{3 c}$ being less than 10\% throughout the overall migration process. This is also evident based on the rate constants where $\mathrm{k}_{2}<\mathrm{k}-2$. Over time, 3d then becomes the major migration product, which is also expected based on the earlier investigations on monosaccharides.29,30 Finally, the acetyl group is then hydrolyzed from 0-6. 
Scheme 2. Acetyl group migration and hydrolysis in the monosaccharides 3 and 4.

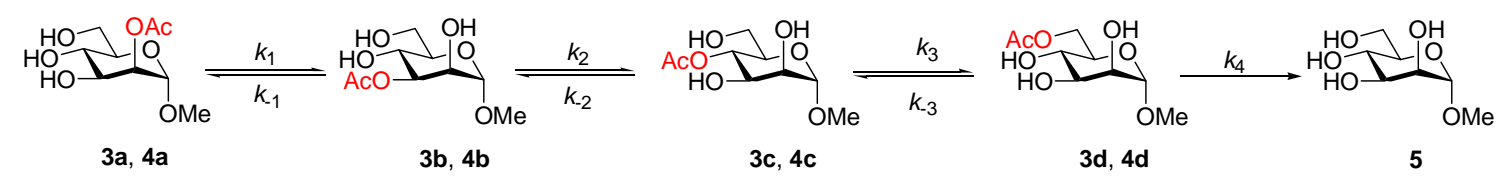

Table 1. Rate constants and the isotope effect of the monosaccharides in different buffers.

\begin{tabular}{|c|c|c|c|c|c|}
\hline & $3^{a}\left(h^{-1}\right)$ & $4^{a}\left(h^{-1}\right)$ & $3^{b}\left(h^{-1}\right)$ & $k\left({ }^{12} C\right) / k\left({ }^{13} C\right)$ & $k\left({ }^{1} \mathrm{H}\right) / k\left({ }^{2} \mathrm{H}\right)$ \\
\hline $\mathbf{k}_{1}$ & $0.566 \pm 0.0068$ & $0.557 \pm 0.0064$ & $0.990 \pm 0.0364$ & 1.02 & 1.75 \\
\hline k-1 & $0.395 \pm 0.0058$ & $0.406 \pm 0.0057$ & $0.672 \pm 0.0292$ & 0.97 & 1.70 \\
\hline $\mathbf{k}_{2}$ & $0.036 \pm 0.0015$ & $0.040 \pm 0.0018$ & $0.066 \pm 0.0028$ & 0.89 & 1.83 \\
\hline $\mathbf{k}-\mathbf{2}$ & $0.091 \pm 0.0127$ & $0.106 \pm 0.0131$ & $0.200 \pm 0.0262$ & 0.85 & 2.21 \\
\hline $\mathbf{k}_{3}$ & $0.300 \pm 0.0125$ & $0.258 \pm 0.0093$ & $1.146 \pm 0.1632$ & 1.16 & 3.82 \\
\hline $\mathbf{k}-3$ & $0.019 \pm 0.0020$ & $0.016 \pm 0.0017$ & $0.072 \pm 0.0140$ & 1.15 & 3.80 \\
\hline $\mathbf{k}_{4}$ & $0.002 \pm 0.0001$ & $0.002 \pm 0.0001$ & $0.002 \pm 0.0001$ & 0.96 & 0.97 \\
\hline
\end{tabular}

aThe migration experiment was followed at $\mathrm{pD}=8$ and $25^{\circ} \mathrm{C}$ in buffered $\mathrm{D}_{2} \mathrm{O} .{ }^{\mathrm{b}}$ The migration experiment was followed at $\mathrm{pH}=8$ and $25{ }^{\circ} \mathrm{C}$ in buffered $\mathrm{H}_{2} \mathrm{O}$ with $10 \% \mathrm{D}_{2} \mathrm{O}$.

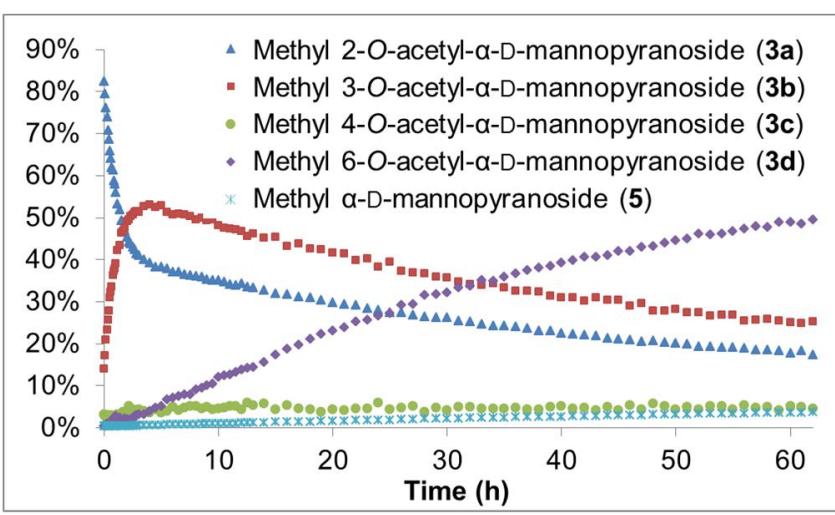

Figure 7. Acetyl group migration in the monosaccharide model compound 3 at $\mathrm{pD}=8$ and $25{ }^{\circ} \mathrm{C}$ in buffered $\mathrm{D}_{2} \mathrm{O}$.

The ${ }^{13}$-labeled monosaccharide 4 was next investigated in the same buffer. The migration followed a similar pattern as observed for the first monosaccharide experiment (For details and illustrations, see Supporting Information). As summarized in Table 1, any ${ }^{13} \mathrm{C} /{ }^{12} \mathrm{C}$ kinetic isotope effect was not observed and the overall ratio between the rate constants is close to 1 . Consequently, it becomes evident that the rate limiting step of the migration process does not involve the cleavage and formation of the $\mathrm{C}$-O bonds at the carbonyl carbon, but rather deprotonation of the hydroxyl group, as also suggested by the DFT modeling of the migration in the trisaccharide model compound.

In order to investigate the deprotonation process, an alternative buffer solution was prepared using $\mathrm{H}_{2} \mathrm{O}$ instead of $\mathrm{D}_{2} \mathrm{O}$. The $\mathrm{H}_{2} \mathrm{O}$ buffer was otherwise similar to the earlier used $\mathrm{D}_{2} \mathrm{O}$ buffer, but contained the corresponding nondeuterated acid and base in order to obtain the same properties. In the initial $\mathrm{D}_{2} \mathrm{O}$ buffer all protons of the carbohydrate hydroxyl will be exchanged to deuterium. ${ }^{38}$ Thus, for studying the ${ }^{1} \mathrm{H}$ isotope in the hydroxyl groups such exchange possibilities should be limited. The migration in the $\mathrm{H}_{2} \mathrm{O}$ buffer followed otherwise a similar pattern as observed in the other monosaccharide experiments, but was considerably faster (for details and illustrations, see Supporting Information). The representative Figure 8 clearly demonstrates the faster migration in the $\mathrm{H}_{2} \mathrm{O}$ buffer compared to the other two experiments where $\mathrm{D}_{2} \mathrm{O}$ was used. Further, as summarized in Table 1 , the rate constant for ${ }^{1} \mathrm{H}$ is always higher compared to deuterium, except for the hydrolysis step. The average ${ }^{1} \mathrm{H} /{ }^{2} \mathrm{H}$ ratio is approximately 2.5 , without considering the $\mathrm{k}_{4}$ where the protons are not involved in the rate determining step. The observed primary isotope effect in the monosaccharide model compound thus provides clear experimental evidence for deprotonation being the rate limiting step in acetyl group migration in polyhydroxyl compounds. This is further supported by the earlier studied migration processes where the migration rate was dependent on the pD of the buffer solution..$^{29}$

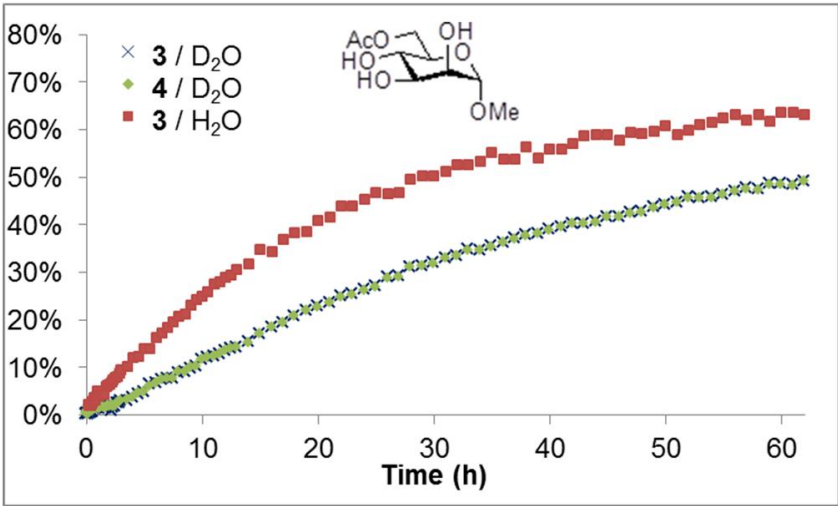

Figure 8. The migration percentage of AcO-6 for $\mathbf{3}$ and $\mathbf{4}$ at $\mathrm{pD} / \mathrm{H}=8$ and $25{ }^{\circ} \mathrm{C}$ in buffered $\mathrm{D}_{2} \mathrm{O} / \mathrm{H}_{2} \mathrm{O}$. 
Finally, it can be observed from Table 1 that for each reversible migration step the $\mathrm{k}\left({ }^{1} \mathrm{H}\right) / \mathrm{k}\left({ }^{2} \mathrm{H}\right)$ ratios of the forward and backward rate constants are of similar magnitude but clearly different depending on the migration step in question, i.e. $\mathrm{k}_{1} / \mathrm{k}_{-1}=1.75 / 1.70$ for the $3 \mathbf{a} / \mathbf{4} \mathbf{a} \leftrightarrow \mathbf{3 b} / \mathbf{4 b}$ migration, $\mathrm{k}_{2} / \mathrm{k}_{2}=1.83 / 2.21$ for the $\mathbf{3 b} / \mathbf{4 b} \leftrightarrow \mathbf{3 c} / \mathbf{4 c}$ migration, and the largest $\mathrm{k}_{3} / \mathrm{k}_{-3}=3.82 / 3.80$

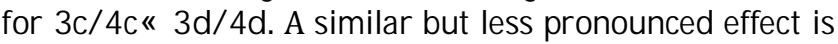
observed also for the different carbon isotopes. Further studies are however needed to investigate this observation in more detail.

\section{Conclusion}

The aim of this investigation was to shed light on the acetyl group migration processes taking place in naturally occurring, partially acetylated polysaccharides by use of appropriately designed, synthetic oligosaccharide model compounds. For the first time it could be demonstrated, that the acetyl groups may also migrate between the different monosaccharide units in an oligosaccharide, across a glycosidic bond. Here, we have combined experimental studies with state of the art quantum mechanical calculations, thus providing valuable insights on the mechanism of this migration process. This previously unknown phenomenon, after more detailed future studies, could have an impact on our understanding of biological activities and biological processes taking place in nature. Migration between the different saccharide units could tentatively be linked to, for example, activation and deactivation of the signaling processes and the biological activities of plants, and the overall role of partial acetylation in natural polysaccharides. While the overall intramolecular migration process across the glycosidic bond, as demonstrated here, could intuitively be considered as slow, in the lifespan perspective of common plants it might nevertheless be significant for the biosignaling processes during the development, regulation and growth of the organism.

Notably, the conditions applied in our experiments are similar to those in the cytoplasm of plant cells, where $\mathrm{pH}$ resides between 7-8. The variation of the $\mathrm{pH}$ depends on both the surrounding conditions and the type of plant. It has also been reported that the $\mathrm{pH}$ in cells increases during growth and development of the organism. ${ }^{34}$ Consequently, in future work, it would be important to investigate the influence of small changes in the $\mathrm{pH}$ on the kinetics of the migration phenomenon. Yet another important aspect for further studies involves the understanding of the significance of the migration process by comparing the biological activities between the starting compound and the migration products. This could be investigated, for example, by measuring the affinities of the starting material and the migration products towards suitable proteins by NMR spectroscopic methods or mass spectrometry.

\section{EXPERIMENTAL SECTION}

General. For following the migration process, a Bruker Avance-III spectrometer operating at $500.20 \mathrm{MHz}\left({ }^{1} \mathrm{H}\right)$ and $125.78 \mathrm{MHz}\left({ }^{13} \mathrm{C}\right)$ equipped with a Smartprobe: $\mathrm{BB} / 1 \mathrm{H}$ was used and for identification and characterization of the new compounds a Bruker Avance-III spectrometer operating at $500.20 \mathrm{MHz}\left({ }^{1} \mathrm{H}\right)$ and $125.78 \mathrm{MHz}\left({ }^{13} \mathrm{C}\right)$ equipped with a
Prodigy BBO CryoProbe or a Bruker Avance-III spectrometer operating at $600.16 \mathrm{MHz}\left({ }^{1} \mathrm{H}\right)$ and 150.91 $\mathrm{MHz}\left({ }^{13} \mathrm{C}\right)$ equipped with a Prodigy TCI CryoProbe was used. The characterization was performed using a standard set of 1D and 2D NMR spectroscopic techniques: ${ }^{1} \mathrm{H},{ }^{13} \mathrm{C}, 1 \mathrm{D}-$ TOCSY, DQF-COSY, Multiplicity edited HSQC $\left(\mathrm{CH}\right.$ and $\mathrm{CH}_{3}$ positive, $\mathrm{CH}_{2}$ negative, both coupled and decoupled), and HMBC

Preparation of buffer solutions. For monitoring the acyl group migration by NMR spectroscopy, a phosphate buffer was used. First a $10 \mathrm{mM} \mathrm{Na}_{2} \mathrm{HPO}_{4}$ buffer with $\mathrm{D}_{2} \mathrm{O}$ was prepared. According to earlier studies, $\mathrm{pD}$ can be solved from $\mathrm{pH}$ by the equation $\mathrm{pD}=\mathrm{pH}+0.4 .{ }^{39,40}$ Consequently, the $\mathrm{pH}$ of the buffer solution was adjusted to 7.6 with $\mathrm{NaOD}$ and $\mathrm{D}_{3} \mathrm{PO}_{4}$. The $\mathrm{H}_{2} \mathrm{O}$ buffer, with $10 \% \mathrm{D}_{2} \mathrm{O}$, was prepared with the corresponding non-deuterated acid and base when the $\mathrm{pH}$ was adjusted to 8. In each migration study $1-11 \mathrm{mg}$ of the corresponding compound ( $\mathbf{1 - 4}$ ) was dissolved in 0.5 $-1 \mathrm{ml}$ buffer solution.

Migration kinetics and modelling. The reaction kinetics for the acetyl group migration for disaccharide was described with a reversible first order reaction scheme as:

$r_{1}=k_{1} * c(\mathbf{1 a})-k_{-1} * c(\mathbf{1} \boldsymbol{b})$

To estimate the forward and backward rate constants the ideal batch reactor model

$$
\frac{d c_{1 a}}{d t}=-r_{1} \quad \frac{d c_{1 b}}{d t}=+r_{1}
$$

was used.

The model for the monosaccharides $\mathbf{3}$ and $\mathbf{4}$ was described in the same way and the reaction scheme was

$$
\begin{aligned}
& r_{1}=k_{1} * c(\mathbf{X} \boldsymbol{a})-k_{-1} * c(\mathbf{X} \boldsymbol{b}) \\
& r_{2}=k_{2} * c(\mathbf{X b})-k_{-2} * c(\mathbf{X c}) \\
& r_{3}=k_{3} * c(\mathbf{X c})-k_{-3} * c(\mathbf{X d}) \\
& r_{4}=k_{4} * c(\mathbf{X d})
\end{aligned}
$$

,where $\mathbf{X}$ is compound $\mathbf{3}$ or $\mathbf{4}$.

And the mass balances become

$$
\begin{gathered}
\frac{d c_{\mathrm{Xa}}}{d t}=-r_{1} \\
\frac{d c_{\mathrm{Xb}}}{d t}=r_{1}-r_{2} \\
\frac{d c_{\mathrm{Xc}}}{d t}=r_{2}-r_{3} \\
\frac{d c_{\mathrm{Xd}}}{d t}=r_{3}-r_{4} \\
\frac{d c_{5}}{d t}=r_{4}
\end{gathered}
$$

The differential equations are solved with the backward difference method as a subtask to the optimizing methods (Simplex and/ or Levenberg-Marquardt) with the software Modest. ${ }^{41}$ As objective function the sum of square function

$$
S S Q=\sum_{t} \sum_{i}\left(c_{i, t, \text { model }}-c_{i, t, \text { experiment }}\right)^{2}
$$

was used. The fit of model to experimental data was good and the fit is displayed in the Supporting Information.

Computational details. The molecular structures were optimized at density functional theory (DFT) level using the 
hybrid Tao-Perdew-Staroverov-Scuseria functional corrected for dispersion interactions, TPSSh-D3(BJ).42-45 For $1 \mathbf{a}$ and $\mathbf{1 b}$ the def2-TZVPP basis set ${ }^{46}$ was employed, for 2a, 2TS, and 2b, the def2-SVP(D) basis set was used; (D) denotes that additional diffuse functions ${ }^{47}$ were added to the $\mathrm{O}-\mathrm{C}-\mathrm{O}$ three-member bridge of the transition state. The transition state 2TS was located with Woelfling reaction path method. ${ }^{48}$ Solvation effects were accounted for with the COSMO model, ${ }^{49}$ using a dielectric constant $\varepsilon=$ 78, simulating a water solvent. Final electronic energies were computed at the coupled cluster singles, doubles and perturbative triples level, employing the domain-based local pair natural orbital approximation, DLPNO-CCSD(T.50 The correlation energy was extrapolated toward basis set completeness using the two-point scheme of Halkier et al, ${ }^{51}$ based on def2-TZVPP(D)/ QZVPP(D) energies; for 1a/1b, diffuse functions were included on all atoms. Free energies were estimated from the harmonic vibrational frequencies, with possible low-frequency modes below $20 \mathrm{~cm}^{-1}$ set to $20 \mathrm{~cm}^{-1}$. For the $\mathbf{1 a} / \mathbf{1 b}$ isomer energy differences, frequencies were computed in gas phase, and $\Delta G$ solvation corrections using the COSMO-RS method. ${ }^{52,53}$ The DFT calculations were performed with Turbomole,54,55 the $\operatorname{CCSD}(\mathrm{T})$ calculations with Orca, ${ }^{56}$ and the COSMO-RS calculations with $\mathrm{ADF} .{ }^{57}$

\section{ASSOCIATED CONTENT}

Supporting Information. The Supporting Information is available free of charge on the ACS Publications website at http:/ / pubs.acs.org.

The supporting information includes: experimental procedures, supporting figures, NMR spectra, kinetic models, atomic coordinates (PDF); animation of the migration between the monosaccharides (AVI).

\section{AUTHOR INFORMATION}

\section{Corresponding Author}

*E-mail: reko.leino@abo.fi

\section{Funding Sources}

The authors thank the Magnus Ehrnrooth foundation, Waldemar von Frenckells foundation, Ruth and Nils-Erik Stenbäck foundation and the Academy of Finland (project 289179).

\section{ACKNOWLEDGMENT}

Computing resources were provided by CSC-The Finnish IT Centre for Science and the Finnish Grid and Cloud Infrastructure (urn:nbn:fi:research-infras-2016072533).

\section{ABBREVIATIONS}

DFT, density function theory; GGM, Galactoglucomannan; TOCSY, total correlated spectroscopy; HSQC, heteronuclear single quantum coherence spectroscopy; HMBC, heteronuclear multiple bond correlation.

\section{REFERENCES}

(1) Kiefer, L. L.; York, W. S.; Darvill, A. G.; Albersheim, P. Xyloglucan Isolated from Suspension-Cultured Sycamore Cell Walls Is O-Acetylated. Phytochemistry 1989, 28, 2105-2107.

(2) Hoffman, M.; Jia, Z.; Peña, M. J.; Cash, M.; Harper, A.; Blackburn, A. R.; Darvill, A.; York, W. S. Structural Analysis of
Xyloglucans in the Primary Cell Walls of Plants in the Subclass Asteridae. Carbohydr. Res. 2005, 340, 1826-1840.

(3) Jia, Z.; Cash, M.; Darvill, A. G.; York, W. S. NMR Characterization of Endogenously O-Acetylated Oligosaccharides Isolated from Tomato (Lycopersicon Esculentum) Xyloglucan. Carbohydr. Res. 2005, 340, 1818-1825.

(4) Gibeaut, D. M.; Pauly, M.; Bacic, A.; Fincher, G. B. Changes in Cell Wall Polysaccharides in Developing Barley (Hordeum Vulgare) Coleoptiles. Planta 2005, 221, 729-738.

(5) Ishii, T. Acetylation at 0-2 of Arabinofuranose Residues in Feruloylated Arabinoxylan from Bamboo Shoot Cell-Walls. Phytochemistry 1991, 30, 2317-2320.

(6) Kabel, M. A.; De Waard, P.; Schols, H. A.; Voragen, A. G. J. Location of O-Acetyl Substituents in Xylo-Oligosaccharides Obtained from Hydrothermally Treated Eucalyptus Wood. Carbohydr. Res. 2003, 338, 69-77.

(7) Teleman, A.; Lundqvist, J.; Tjerneld, F.; Stålbrand, H.; Dahlman, O. Characterization of Acetylated 4-OMethylglucuronoxylan Isolated from Aspen Employing ${ }^{1} \mathrm{H}$ And ${ }^{13} \mathrm{C}$ NMR Spectroscopy. Carbohydr. Res. 2000, 329, 807-815.

(8) Femenia, A.; Sánchez, E. S.; Simal, S.; Rosselló, C. Compositional Features of Polysaccharides from Aloe Vera (Aloe Barbadensis Miller) Plant Tissues. Carbohydr. Polym. 1999, 39, 109-117.

(9) Kenne, L.; Rosell, K.-G.; Svensson, S. Studies on the Distribution of the O-Acetyl Groups in Pine Glucomannan. Carbohydr. Res. 1975, 44, 69-76.

(10) Xing, X.; Cui, S. W.; Nie, S.; Phillips, G. O.; Goff, H. D.; Wang, Q. Study on Dendrobium Officinale O-Acetyl-Glucomannan (Dendronan $\left.{ }^{\circledR}\right)$ : Part I. Extraction, Purification, and Partial Structural Characterization. Bioact. Carbohydrates Diet. Fibre 2014, 4, 74-83.

(11) Xing, X.; Cui, S. W.; Nie, S.; Phillips, G. O.; Goff, H. D.; Wang, Q. Study on Dendrobium Officinale O-Acetyl-Glucomannan (Dendronan ${ }^{\circledR}$ ): Part II. Fine Structures of O-Acetylated Residues. Carbohydr. Polym. 2015, 117, 422-433.

(12) Willför, S.; Sjöholm, R.; Laine, C.; Roslund, M.; Hemming, J.; Holmbom, B. Characterisation of Water Soluble Galactoglucomannans from Norway Spruce Wood and Thermomechanical Pulp. Carbohydr. Polym. 2003, 52, 175-187.

(13) Nunes, F. M.; Domingues, M. R.; Coimbra, M. A. Arabinosyl and Glucosyl Residues as Structural Features of Acetylated Galactomannans from Green and Roasted Coffee Infusions. Carbohydr. Res. 2005, 340, 1689-1698.

(14) Pauly, M.; Keegstra, K. Plant Cell Wall Polymers as Precursors for Biofuels. Curr. Opin. Plant Biol. 2010, 13, 305-312.

(15) Liners, F.; Gaspar, T.; Van Cutsem, P. Acetyl- and MethylEsterification of Pectins of Friable and Compact Sugar-Beet Calli: Consequences for Intercellular Adhesion. Planta 1994, 192, 545556 .

(16) Obel, N.; Erben, V.; Schwarz, T.; Kühnel, S.; Fodor, A.; Pauly, M. Microanalysis of Plant Cell Wall Polysaccharides. Mol. Plant 2009, 2, 922-932.

(17) Pauly, M.; Eberhard, S.; Albersheim, P.; Darvill, A.; York, W. S. Effects of the Mur1 Mutation on Xyloglucans Produced by Suspension-Cultured Arabidopsis Thaliana Cells. Planta 2001, 214, 67-74.

(18) Petkowicz, C. L. O.; Reicher, F.; Mazeau, K. Conformational Analysis of Galactomannans: From Oligomeric Segments to Polymeric Chains. Carbohydr. Polym. 1998, 37, 25-39.

(19) Petkowicz, C. L. O.; Reicher, F.; Chanzy, H.; Taravel, F. R.; Vuong, R. Linear Mannan in the Endosperm of Schizolobium Amazonicum. Carbohydr. Polym. 2001, 44, 107-112.

(20) Meier, H.; Reid, J. S. G. Reserve Polysaccharides Other Than Starch in Higher Plants BT - Plant Carbohydrates I: Intracellular Carbohydrates; Loewus, F. A., Tanner, W., Eds.; Springer Berlin Heidelberg: Berlin, Heidelberg, 1982; pp 418-471.

(21) Huang, X.; Nie, S.; Cai, H.; Zhang, G.; Cui, S. W.; Xie, M.; Phillips, G. O. Study on Dendrobium Officinale O-AcetylGlucomannan (Dendronan ${ }^{\circledR}$ ): Part VI. Protective Effects against 
Oxidative Stress in Immunosuppressed Mice. Food Res. Int. 2015, $72,168-173$.

(22) Zhang, G. Y.; Nie, S. P.; Huang, X. J.; Hu, J. L.; Cui, S. W.; Xie, M. Y.; Phillips, G. O. Study on Dendrobium Officinale O -AcetylGlucomannan (Dendronan ${ }^{\circledR}$ ). 7. Improving Effects on Colonic Health of Mice.J. Agric. Food Chem. 2016, 64, 2485-2491.

(23) Huang, X.; Nie, S.; Cai, H.; Zhang, G.; Cui, S. W.; Xie, M.; Phillips, G. O. Study on Dendrobium Officinale O-AcetylGlucomannan (Dendronan ${ }^{\circledR}$ ): Part IV. Immunomodulatory Activity in Vivo.J. Funct. Foods 2015, 15, 525-532.

(24) Willför, S.; Sundberg, K.; Tenkanen, M.; Holmbom, B Spruce-Derived Mannans - A Potential Raw Material for Hydrocolloids and Novel Advanced Natural Materials. Carbohydr. Polym. 2008, 72, 197-210.

(25) Willför, S.; Sundberg, A.; Pranovich, A.; Holmbom, B Polysaccharides in Some Industrially Important Hardwood Species. Wood Sci. Technol. 2005, 39, 601-617.

(26) Ebringerová, A.; Hromádková, Z;; Hříbalová, V.; Xu, C.; Holmbom, B.; Sundberg, A.; Willför, S. Norway Spruce Galactoglucomannans Exhibiting Immunomodulating and RadicalScavenging Activities. Int. J. Biol. Macromol. 2008, 42, 1-5.

(27) Portaleone, P. Acetylation. In Encyclopedia of Endocrine Diseases; Elsevier, 2004; pp 9-12.

(28) Fischer, E. Wanderung von Acyl Bei Den Glyceriden. Ber. Dtsch. Chem. Ges. 1920, 53, 1621-1633.

(29) Roslund, M. U.; Aitio, O.; Wärnå, J.; Maaheimo, H.; Murzin D. Yu.; Leino, R. Acyl Group Migration and Cleavage in Selectively Protected $\beta$-D-Galactopyranosides as Studied by NMR Spectroscopy and Kinetic Calculations. J. Am. Chem. Soc. 2008, 130, 8769-8772.

(30) Brecker, L.; Manut, M.; Schwarz, A.; Nidetzky, B. In Situ Proton NMR Study of Acetyl and Formyl Group Migration in MonoO-Acyl D-Glucose. Magn. Reson. Chem. 2009, 47, 328-332.

(31) Yoshimoto, K.; Tsuda, Y. General Path of O-Acyl Migration in d-Glucose Derivatives: Acyl Migration of Methyl Mono-OMyristoyl- $\alpha$ - and $\beta$-D-Glucopyranosides and Mono-O-Myristoyl-DGlucopyranoses. Chem. Pharm. Bull. 1983, 31, 4324-4334.

(32) Ohara, K.; Lin, C. C.; Yang, P. J.; Hung, W. T.; Yang, W. Bin; Cheng, T. J. R.; Fang, J. M.; Wong, C. H. Synthesis and Bioactivity of $\beta$ - $(1 \rightarrow 4)$-Linked Oligomannoses and Partially Acetylated Derivatives. J. Org. Chem. 2013, 78, 6390-6411.

(33) Puchart, V.; Agger, J. W.; Berrin, J. G.; Várnai, A.; Westereng, B.; Biely, P. Comparison of Fungal Carbohydrate Esterases of Family CE16 on Artificial and Natural Substrates. J. Biotechnol. 2016, 233, 228-236.

(34) Guern, J.; Felle, H.; Mathieu, Y.; Kurkdjian, A. Regulation of Intracellular $\mathrm{pH}$ in Plant Cells. Int. Rev. Cytol. 1991, 127, 111173.

(35) Capek, P.; Alföldi, J.; Lišková, D. An Acetylated Galactoglucomannan from Picea Abies L. Karst. Carbohydr. Res. 2002, 337, 1033-1037.

(36) Woods, R. J.; Pathiaseril, A.; Wormald, M. R.; Edge, C. J.; Dwek, R. A. The High Degree of Internal Flexibility Observed for an Oligomannose Oligosaccharide Does Not Alter the Overall Topology of the Molecule. Eur. J. Biochem. 1998, 258, 372-386.

(37) Hammond, G. S. A Correlation of Reaction Rates. J. Am. Chem. Soc. 1955, 77, 334-338.

(38) Anslyn, E. V.; Dougherty, D. A. Modern Physical Organic Chemistry; University Science Books: Sausalito, Carlifornia, 2006.

(39) Bastardo, L. A.; Mészaros, R.; Varga, I.; Gilányi, T.; Cleasson, P. M. Deuterium Isotope Effects on the Interaction between Hyperbranched Polyethylene Imine and an Anionic Surfactant. J. Phys. Chem. B 2005, 109, 16196-16202.

(40) Mikkelsen, K.; Siguri, A.; Nielsen, O. Acidity Measurements with the Glass Electrode Is $\mathrm{H}_{2} \mathrm{O}-\mathrm{D}_{2} \mathrm{O}$ Mixtures. J. Phys. Chem. 1952, 458, 1-6.

(41) Haario, H. Modest 6.0- A Users's Guide. ProMath: Helsinki 2001.

(42) Staroverov, V. N.; Scuseria, G. E.; Tao, J.; Perdew, J. P. Comparative Assessment of a New Nonempirical Density
Functional: Molecules and Hydrogen-Bonded Complexes. J. Chem. Phys. 2003, 119, 12129-12137.

(43) Grimme, S.; Antony, J.; Ehrlich, S.; Krieg, H. A Consistent and Accurate $\mathrm{Ab}$ Initio Parametrization of Density Functional Dispersion Correction (DFT-D) for the 94 Elements H-Pu. J. Chem. Phys. 2010, 132, 154104

(44) Becke, A. D.; Johnson, E. R. A Density-Functional Model of the Dispersion Interaction. J. Chem. Phys. 2005, 123, 154101.

(45) Grimme, S.; Ehrlich, S.; Goerigk, L. Effect of the Damping Function in Dispersion Corrected Density Functional Theory. J Comput. Chem. 2011, 32, 1456-1465.

(46) Weigend, F.; Ahlrichs, R. Balanced Basis Sets of Split Valence, Triple Zeta Valence and Quadruple Zeta Valence Quality for $\mathrm{H}$ to Rn: Design and Assessment of Accuracy. Phys. Chem. Chem. Phys. 2005, 7, 3297-3305.

(47) Rappoport, D.; Furche, F. Property-Optimized Gaussian Basis Sets for Molecular Response Calculations. J. Chem. Phys. 2010, 133, 134105

(48) Plessow, P. Reaction Path Optimization without NEB Springs or Interpolation Algorithms. J. Chem. Theory Comput. 2013, 9, 1305-1310.

(49) Klamt, A.; Schüürman, G. Cosmo - a New Approach To Dielectric Screening in Solvents With Explicit Expressions for the Screening Energy and Its Gradient. J. Chem. Soc. Trans. 2 1993, 799-805.

(50) Riplinger, C.; Pinski, P.; Becker, U.; Valeev, E. F.; Neese, F. Sparse Maps - A Systematic Infrastructure for Reduced-Scaling Electronic Structure Methods. II. Linear Scaling Domain Based Pair Natural Orbital Coupled Cluster Theory. J. Chem. Phys. 2016, 144, 024109.

(51) Halkier, A.; Helgaker, T.; Jørgensen, P.; Klopper, W.; Koch H.; Olsen, J.; Wilson, A. K. Basis-Set Convergence in Correlated Calculations on Ne, N2, and H2O. Chem. Phys. Lett. 1998, 286, 243252.

(52) Klamt, A. Conductor-like Screening Model for Real Solvents: A New Approach to the Quantitative Calculation of Solvation Phenomena. J. Phys. Chem. 1995, 99, 2224-2235.

(53) Pye, C. C.; Ziegler, T. An Implementation of the Conductor-like Screening Model of Solvation within the Amsterdam Density Functional Package. Theor. Chem. Acc. 1999, 101, 396-408.

(54) Turbomole V7.1-V7.3 2016-2018. a development of University of Karlsruhe and Forschungszentrum Karlsruhe $\mathrm{GmbH}$ 1989-2007, TURBOMOLE GmbH, since 2007; available from http:// www.turbomole.com

(55) Ahlrichs, R.; Bär, M.; Häser, M.; Horn, H.; Kölmel, C. Electronic Structure Calculations on Workstation Computers: The Program System Turbomole. Chem. Phys. Lett. 1989, 162, 165-169.

(56) Neese, F. Software Update: The ORCA Program System, Version 4.0. Wiley Interdiscip. Rev. Comput. Mol. Sci. 2018, 8, 4-9.

(57) AMS2018 COSMO-RS, SCM, Theoretical Chemistry. Vrije Universiteit, Amsterdam, The Netherlands, http:/ / www.scm.com. 
Table of Contents artwork

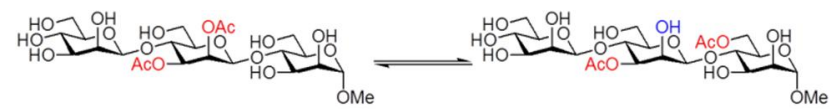

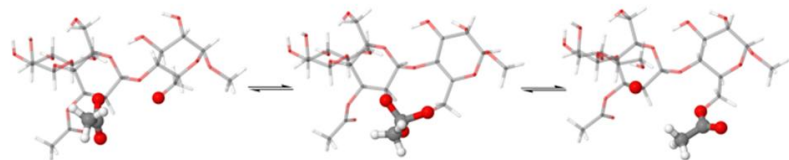

